\title{
Synthesis and characterization of mordenite crystals
}

\author{
M S JOSHI and $\mathrm{K}$ MOHAN PRABHU \\ Physics Department, Sardar Patel University, Vallabh Vidyanagar 388 120, India \\ MS received 10 September 1986; revised 2 January 1987
}

\begin{abstract}
The hydrothermal synthesis of large port mordenite crystals and experimental observations are reported. Unit cell parameters are estimated as $a=18.142, b=20.328$ and $c=7.508 \AA$. Prismatic and prismatic pyramidal mordenite crystals are illustrated. The average particle size computed was $8-20 \mu$. Adsorption capacities of synthesized mordenite crystals are $13.4 \%$ for water, $9.9 \%$ for methanol and $5.8 \%$ for benzene by weight.
\end{abstract}

Keywords. Mordenite; tetrapropylammonium bromide; prismatic pyramidal.

\section{Introduction}

Mordenite is a mineral zeolite, belonging to group $\mathrm{VI}$ and its $\mathrm{Si} / \mathrm{Al}$ ratio is about 5 . It has a twi-dimensional channel system, designated as small port and it adsorbs only small molecules such as methane (Sand 1968) into its 12-membered ring channels (6.7 ̊). The limitation on its diffusion may be because of the presence of amorphous materials or cations in the channels (Breck 1974a). Synthetic mordenite, known as large port mordenite, commonly referred to as zeolon (Sand 1969), exhibits adsorption characteristics expected for free diffusion of molecules in the $6.7 \AA$ diameter 12 membered ring channels (Sand 1968). The high degree of stability shown by mordenite along with its high resistance to acids, finds many applications in adsorption and hydrocarbon conversion catalysis (Csicsery 1984; Burbidge et al 1971; Kranich et al 1971). Since it was first synthesised back using feldspars and alkalicarbonates its synthesis from a variety of starting materials has been reported (Barrer and Denny 1961; Coombs et al 1959; Senderov 1963). Chu (1973) and Chang et al (1975) synthesized mordenite crystals using tetraethylammonium hydroxide. Stewart and Ball (1980) used neopentylamine as templates. The present paper reports observations and results of our efforts to synthesize large port mordenite crystals using tetrapropylammonium bromide in the system $\mathrm{Na}_{2} \mathrm{O}-\mathrm{Al}_{2} \mathrm{O}_{3}-\mathrm{SiO}_{2}-\mathrm{H}_{2} \mathrm{O}$ at $150^{\circ} \mathrm{C}$.

\section{Experimental method}

Colloidal silica $\left(40 \% \mathrm{SiO}_{2}\right.$ in water), sodium aluminate, sodium hydroxide, tetrapropylammonium bromide and double distilled water were used to prepare the gel. A known amount of TPA-Br was dissolved in double-distilled water in a large flask. Aqueous solutions of specific quantities of sodium hydroxide, sodium aluminate and colloidal silica were prepared in separate beakers. These solutions were added, one after the other drop by drop, to the TPA-Br solution in the flask and vigorously stirred during the process. The resulting solution was stirred for $3 \mathrm{hr}$. Its $\mathrm{pH}$ was adjusted to 12 using dilute sulphuric acid. The gel was transferred to the teflon lined autoclave vessel which was then sealed and heated to $150 \pm 2{ }^{\circ} \mathrm{C}$ (at 300 psi) for seven 
days with occasional stirring. The Berghof autoclave used in the present investigation provides for induction-driven PTFE-protected system for stirring the reactants even after sealing the vessel. At the end of the run, the product was filtered and washed repeatedly with double-distilled water. It was then dried at $150^{\circ} \mathrm{C}$ for $12 \mathrm{hr}$. These crystallites were characterized by the following techniques.

\section{Experimental observations}

\subsection{X-ray diffraction studies}

$\mathrm{X}$-ray powder diffractograms were recorded in the range $2 \theta=5-75^{\circ}$ using $\mathrm{CuK}_{\alpha}$. radiation. From the diffractogram, $d$ values and the corresponding relative intensities were calculated. These $d$ values agree with the reported values for large port mordenite (Breck 1974). Unit cell parameters were calculated as $a=18 \cdot 142, b=20.328$ and $c=7.508 \AA$. The crystals belong to an orthorhombic system.

\subsection{Infrared spectral studies}

Infrared spectra of our samples were recorded using $\mathrm{KBr}$ wafer technique in the range $300-1300 \mathrm{~cm}^{-1}$. Band assignment was done according to Flanigen (1976). The infrared spectrum is shown in figure 1 . Bands were grouped into two classes. In one class, bands were structure-sensitive and were due to internal vibrations of $\mathrm{TO}_{4}$

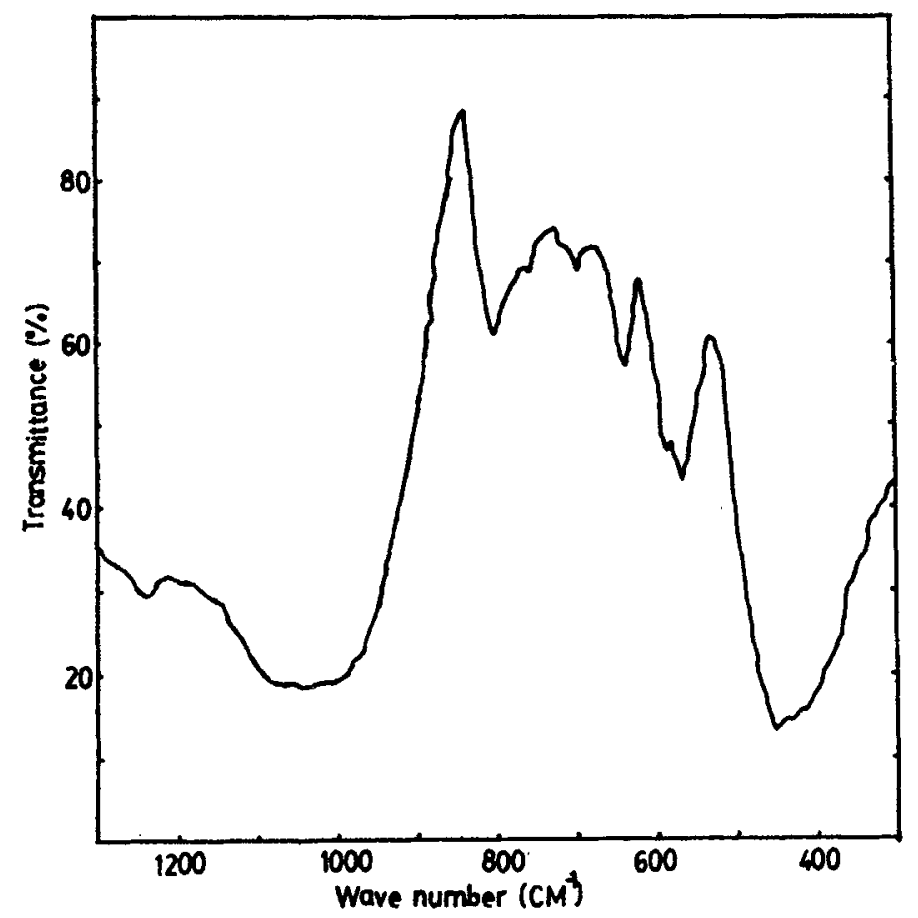

Figure 1. Infrared spectrum. 
tetrahedron, the primary unit of structure. The band at $1045 \mathrm{~cm}$ : (vs) was caused by an asymmetric stretch and the band at $450 \mathrm{~cm}{ }^{1}$ (vs) was due to the T-O bending mode. Two bands at $755 \mathrm{~cm}^{1}$ (vvw) and $696 \mathrm{~cm}^{-1}$ (vw) were caused by symmetric stretching modes involving tetrahedral atoms. The other class of bands was structuresensitive. The bands at $565 \mathrm{~cm}^{-1}$ (ms), $585 \mathrm{~cm}{ }^{1}(\mathrm{w}), 635 \mathrm{~cm}{ }^{1}(\mathrm{mw})$ and $1240 \mathrm{~cm}^{-1}$ $(\mathrm{m} \mathrm{sh})$ were due to 5 -membered ring chain. The band at $800 \mathrm{~cm}^{-1}(\mathrm{mw})$ was caused by symmetric stretching mode.

\subsection{Elemental analysis}

The samples were characterized by energy dispersive analysis of $x$-rays (EDAX). Atomic percentages of sodium, aluminium and silicon were found to be $8.966,12.849$
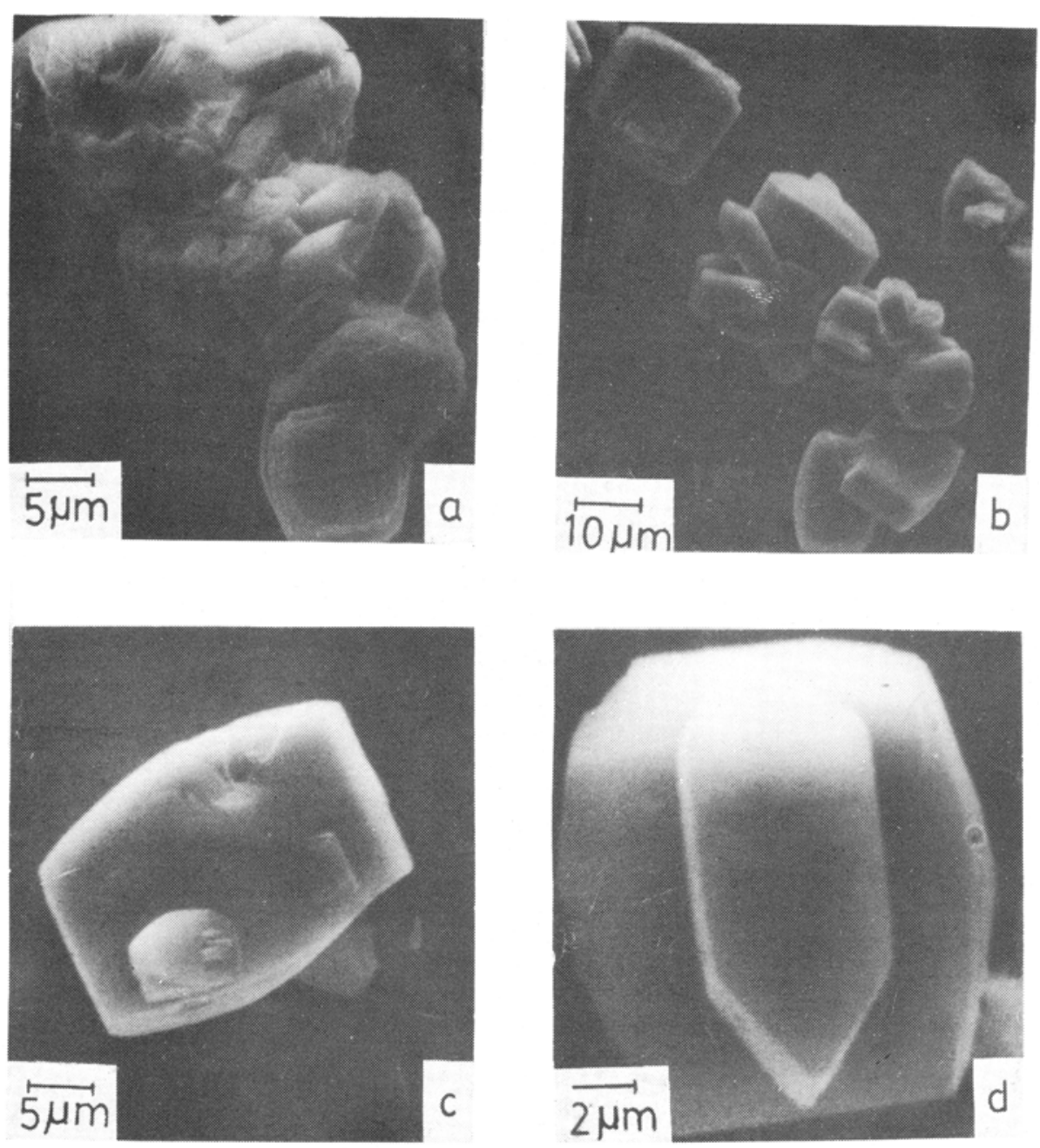

Figure 2. Scanning electron micrographs of mordenite crystals. (a) Crystal aggregates. (b) Some isolated and some aggregate crystals. (c) A prismatic crystal with two small crystals on its surface. (d) A prismatic pyramidal crystal on the surface of a prismatic crystal. 


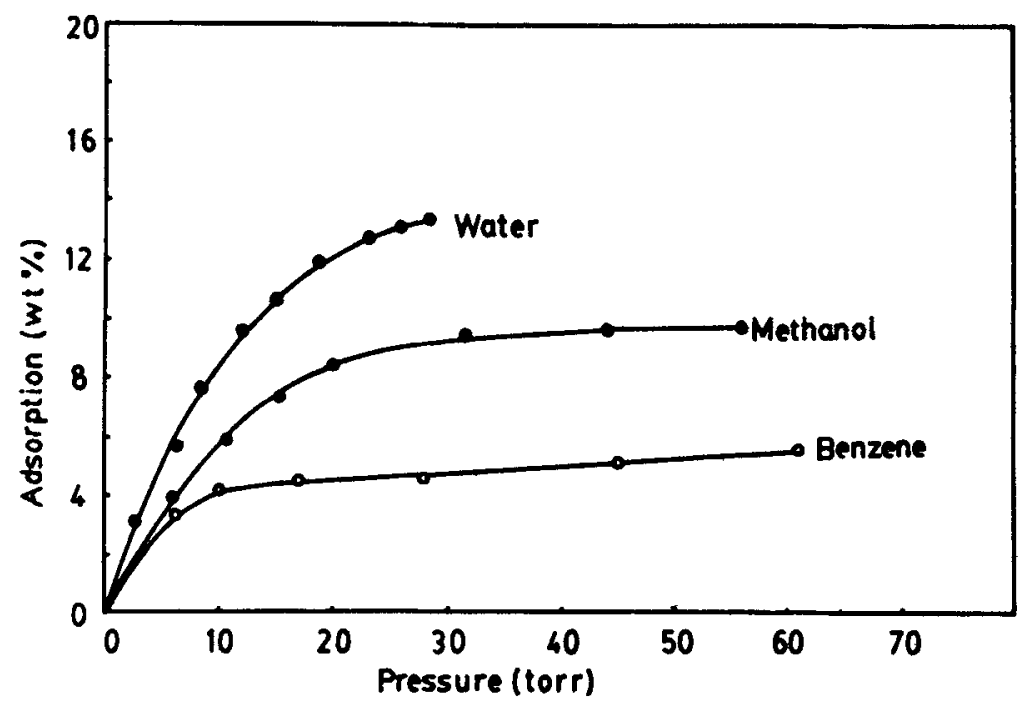

Figure 3. Adsorption curves.

and $78 \cdot 185$ respectively. The $\mathrm{Si} / \mathrm{Al}$ ratio was 6.09 . The molar oxide formula of the final product was calculated as $3.26 \mathrm{Na}_{2} \mathrm{O} .4 \cdot 67 \mathrm{Al}_{2} \mathrm{O}_{3} .56 \cdot 86 \mathrm{SiO}_{2} \cdot 35 \cdot 20 \mathrm{H}_{2} \mathrm{O}$.

\subsection{SEM studies}

The crystals were coated with gold films and examined under a scanning electron microscope. Figure 2(a) shows crystal aggregates. Some isolated and some crystal aggregates are shown in figure 2 (b). A prismatic crystal with two small crystals on its surface and a prismatic pyramidal crystal on the surface of a prismatic crystal are shown in figures 2 (c) and 2 (d) respectively. The average particle size was calculated as $8-20 \mu$.

\subsection{Adsorption studies}

Using the McBain balance fabricated in this laboratory, adsorption on the calcined (at $550^{\circ} \mathrm{C}$ ) mordenite crystals was carried out at $30^{\circ} \mathrm{C}$. The adsorption curves for water, methanol and benzene are shown in figure 3. It was found that these crystals adsorb $13 \cdot 4 \%$ water, $9.9 \%$ methanol and $5 \cdot 8 \%$ benzene by weight.

\section{Acknowledgement}

The authors thank CSIR, New Delhi for financial support.

\section{References}

Barrer R M and Denny P J $1961 \mathrm{~J}$. Chem. Soc. 983

Breck D W 197 Aa Zeolite molecular sieves (New York: John Wiley) pp. 124, 363 
Burbidge B W, Keen I M and Eyles M K 1971 Molecular sieve zeolites $/$ (Adv. Chem. Ser. 102) 400 Chang C D, Lang W H and Silvestri A J 1975 U S Pat. 3894104

Chu P S 1973 U S Pat. 3766093

Coombs D S, Ellis A J, Fyfe W F and Taylor A M 1959 Geochim. Cosmochim. Acta 1753

Csicsery S M 1984 Zeolites 4202

Flanigen E M 1976 Zeolite chemistry and catalysis (ed) J A Rabo (Adv. Chem. Ser. 171)

Kranich W L, Ma Y H, Sand L B, Weiss A H and Zwiebel I 1971 Molecular sieve zeolites I (Adv. Chem. Ser. 101) 502

Sand L B 1968 Molecular sieves (Soc. Chem. Industry Spec. Publ.) 71

Sand L B 1969 U S Pat. 3436174

Senderov E E 1963 Geokhimiya 9848

Stewart D G and Ball W J 1980 Eur Pat. 14023 